\title{
Bis(imino)pyridine (BIMP) Fe(II) catalyses one-pot green condensation of resorcinol, malononitrile, aromatic aldehydes and cyclohexanone
}

\author{
SAMAN DAMAVANDI ${ }^{\mathrm{a}, *}$ and REZA SANDAROOS ${ }^{\mathrm{b}}$ \\ a Department of Chemistry, Sarvestan Branch, Islamic Azad University, Sarvestan, Iran \\ ${ }^{b}$ Department of Chemistry, Faculty of Science, Birjand University, Birjand, Iran \\ e-mail: Saman_Damavandi@yahoo.com; R_Sandaroos@yahoo.com
}

MS received 17 April 2011; revised 29 July 2011; accepted 8 August 2011

\begin{abstract}
A novel, efficient and green approach for the synthesis of pyranopyridine derivatives through one-pot, four-component reaction of resorcinol, malononitrile, aromatic aldehydes and cyclohexanone using bis(imino)pyridine (BIMP) Fe(II) catalyst under solvent-free and ultrasonic irradiation is described.
\end{abstract}

Keywords. Pyranopyridine; four-component; one-pot; BIMP catalyst.

\section{Introduction}

Benzopyrano[2,3- $b]$ pyridines exhibit cancer chemopreventive, ${ }^{1}$ antibacterial (including antitubercular), ${ }^{2}$ antimyopic, ${ }^{3}$ hypotensive, ${ }^{4}$ antirheumatic, ${ }^{5}$ and antiasthmatic activities. ${ }^{6}$ During the course of studies on the development of new procedures to synthesize substituted pyranopyridine, a few procedures have been reported, for instance, two-step synthesis of pyrano[2,3$b$ ]pyridine derivatives has been reported by Dushyant et al. ${ }^{6}$ 4-[( $N$-Imidazol-2-ylmethyl)anilino]pyranopyridine derivatives were synthesized by Sunkyung et al. ${ }^{7}$ Synthesis of 2-Aryl-4H-pyrano[2,3-b]pyridin-4-ones has been reported by Khlebnikov et al. ${ }^{8}$ However, due to the economical and atom efficiency issues the development of a one-pot, efficient, rapid and convenient protocol for the multicomponent synthesis of pyranopyridines is of remarkable interest.

Ultrasound has been increasingly used in organic synthesis in the last three decades. It has been demonstrated as an alternative energy source for organic reactions ordinarily accomplished by heating. The use of ultrasound irradiation technique for activating various reactions is well-documented in the literature such as Reformatsky reaction, ${ }^{9}$ Pinacol coupling, ${ }^{10}$ Ullmann condensation ${ }^{11}$ and Suzuki cross-coupling. ${ }^{12}$

Schiff base catalysts are versatile catalysts which have been used in many various fields of organic chemistry. Recently, we have studied the catalytic activity and application of 2,6-bis(imino)pyridine catalysts based on iron(II) possessing different substituents. ${ }^{13}$

*For correspondence
In continuation of our study on the development of new routes in heterocyclic synthesis via novel one-pot MCRs, ${ }^{14,15}$ here a novel four-component reaction for the synthesis of pyrano[2,3- $b$ ]pyridine derivatives is reported. Four-component, one-pot reaction of resorcinol, malononitrile, aromatic aldehydes and cyclohexanone was performed in the presence of catalytic amounts of (4-nitro-2,6-diacetylpyridinebis(2,4,6-trimethylanil)) $\mathrm{FeCl}_{2}$ under solvent-free conditions using ultrasonic irradiation (scheme 1).

\section{Experimental}

\subsection{Materials and methods}

Chemicals were either prepared in our laboratories or purchased from Merck, Fluka and Aldrich Chemical Companies. All yields refer to isolated products. IR spectra were recorded on a Shimadzu-IR 470 spectrophotometer. ${ }^{1} \mathrm{H}$ NMR spectra was recorded on a Bruker $100 \mathrm{MHz}$ spectrometer in chloroform as the solvent and TMS as internal standard. Flash column chromatography was performed with 300 and 400 meshes silica gel and analytical thin layer chromatography was performed on pre-coated silica gel plates $(60 \mathrm{~F}-$ 254). Sonication was performed in a Shanghai BransonCQX ultrasonic cleaner with a frequency of $40 \mathrm{kHz}$ and a nominal power of $100 \mathrm{~W}$. The reaction vessel placed inside the ultrasonic bath. Elemental analyses were performed on Thermo Finnigan EA1112 elemental analyser. The procedure for synthesis of 4-nitro2,6-diacetylpyridinebis(2,4,6-trimethylanil)) $\mathrm{FeCl}_{2}$ is reported elsewhere. ${ }^{13}$ 


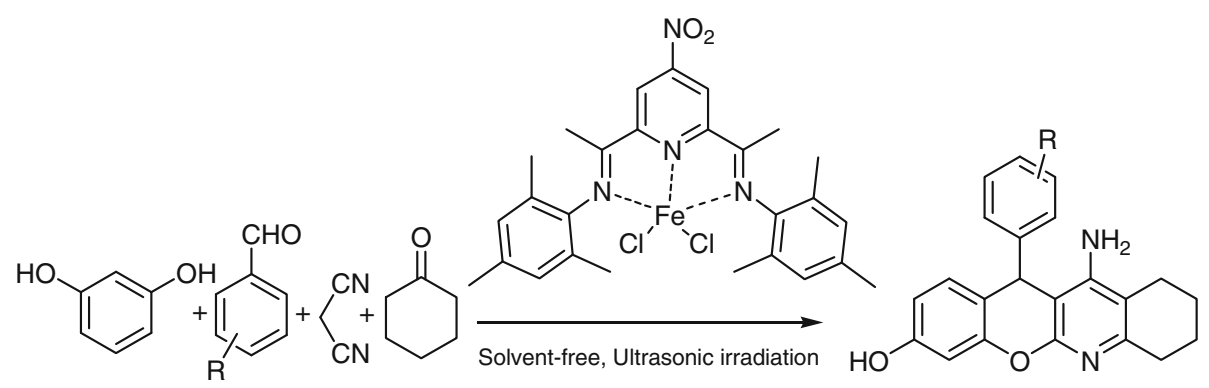

Scheme 1. Multicomponent synthesis of pyrano[2,3-b]pyridine derivatives.

\subsection{General procedure for synthesis} of pyrano[2,3-b]pyridine derivatives

In a round bottom flask a mixture of resorcinol (1 mmol), malononitrile $(1.1 \mathrm{mmol})$, aromatic aldehyde $(1 \mathrm{mmol})$ and cyclohexanone $(1 \mathrm{mmol})$ was mixed with 4-nitro2,6-diacetylpyridinebis(2,4,6-trimethylanil)) $\mathrm{FeCl}_{2}$ $(0.1 \mathrm{mmol})$ and the mixture was irradiated under ultrasonic waves at room temperature for an appropriate time as indicated in table 1 . The progress of the reaction was monitored by TLC. After completion the reaction, the catalyst was filtered, the reaction mixture was then extracted with dichloromethane $(3 \times 10 \mathrm{~mL})$. The organic layer was then washed with water and dried over anhydrous $\mathrm{Na}_{2} \mathrm{SO}_{4}$. Organic solvent was evaporated under reduced pressure and the obtained product was purified by column chromatography to afford the pure products in good to excellent yields. Spectral data for the selected products are as follows:

2.2a 11-Amino-8,9,10,12-tetrahydro-12-phenyl-7Hchromeno[2,3-b]quinolin-1-ol (entry 1): $310-311^{\circ} \mathrm{C}$. IR (KBr): 3440, 3365, 3018, 1614, 1527, 1238, $1111 \mathrm{~cm}^{-1} .{ }^{1} \mathrm{H}$ NMR (100 MHz, DMSO- $\left.d_{6}\right): \delta=1.60$ (m, 4H, $\left.\mathrm{CH}_{2}\right), 2.30\left(\mathrm{~m}, 2 \mathrm{H}, \mathrm{CH}_{2}\right), 2.62\left(\mathrm{~m}, 2 \mathrm{H}, \mathrm{CH}_{2}\right)$, 5.33 (s, 1H, CH), 6.75-7.45 (m, 10H, ArH, $\left.\mathrm{NH}_{2}\right), 9.60$ (s, $1 \mathrm{H}, \mathrm{OH}$ ). Anal. Calcd for $\mathrm{C}_{22} \mathrm{H}_{20} \mathrm{~N}_{2} \mathrm{O}_{2}$ : C, 76.72; $\mathrm{H}$, 5.85; N, 8.13. Found: C, 75.66; H, 5.99; N, 7.95.

Table 1. Results of pyranopyridine derivatives synthesis. ${ }^{a}$

Entry Yield (\%)


Table 1. (continued).

\begin{tabular}{|c|c|c|c|}
\hline Entry & Product & Time (min) & Yield $(\%)^{\mathrm{b}}$ \\
\hline 5 & & 40 & 90 \\
\hline 6 & & 42 & 88 \\
\hline 7 & & 33 & 90 \\
\hline 8 & & 30 & 92 \\
\hline 9 & & 45 & 84 \\
\hline
\end{tabular}

${ }^{\mathrm{a}}$ The reactions were carried out under solvent-free, ultrasonication in the presence of $10 \mathrm{~mol} \%$ catalyst. ${ }^{\mathrm{b}}$ Isolated yields.

2.2b 11-Amino-12-(4-bromophenyl)-8,9,10,12tetrahydro-7H-chromeno[2,3-b]quinolin-1-ol (entry 2): mp: 278-279 ${ }^{\circ}$. IR (KBr): 3434, 3376, 2977, 1607, 1488, 1206, $1167 \mathrm{~cm}^{-1}$. ${ }^{1} \mathrm{H}$ NMR (100 MHz, DMSO$\left.d_{6}\right): \delta=1.64\left(\mathrm{~m}, 4 \mathrm{H}, \mathrm{CH}_{2}\right), 2.28\left(\mathrm{~m}, 2 \mathrm{H}, \mathrm{CH}_{2}\right), 2.55$ $\left(\mathrm{m}, 2 \mathrm{H}, \mathrm{CH}_{2}\right), 5.40(\mathrm{~s}, 1 \mathrm{H}, \mathrm{CH}), 6.35$ (br, $2 \mathrm{H}, \mathrm{NH}_{2}$ ), 6.65-7.40 (m, 7H, ArH), 9.80 (s, 1H, OH). Anal. Calcd for $\mathrm{C}_{22} \mathrm{H}_{19} \mathrm{BrN}_{2} \mathrm{O}_{2}$ : C, 62.42; H, 4.52; N, 6.62. Found: C, 62.17; H, 4.44; N, 6.73 .

2.2c 11-Amino-8,9,10,12-tetrahydro-12-(4-methoxyphenyl)-7H-chromeno[2,3-b]quinolin-1-ol (entry 4): $\mathrm{mp}: 293-295^{\circ} \mathrm{C}$. IR (KBr): 3475, 3388, 2907, 1619, 1455, 1223, $1166 \mathrm{~cm}^{-1}$. ${ }^{1} \mathrm{H}$ NMR (100 MHz, DMSO$\left.d_{6}\right): \delta=1.55\left(\mathrm{~m}, 4 \mathrm{H}, \mathrm{CH}_{2}\right), 2.25\left(\mathrm{~m}, 2 \mathrm{H}, \mathrm{CH}_{2}\right), 2.40$ $\left(\mathrm{m}, 2 \mathrm{H}, \mathrm{CH}_{2}\right), 3.75\left(\mathrm{~s}, 3 \mathrm{H}, \mathrm{OCH}_{3}\right), 5.55(\mathrm{~s}, 1 \mathrm{H}, \mathrm{CH})$, 6.25 (s, 2H, $\mathrm{NH}_{2}$ ), 6.6-7.4 (m, 7H, ArH), 9.75 (s, 1H, $\mathrm{OH}$ ). Anal. Calcd for $\mathrm{C}_{23} \mathrm{H}_{22} \mathrm{~N}_{2} \mathrm{O}_{3}$ : C, 73.78; H, 5.92; N, 7.48. Found: C, 73.52; H, 5.80; N, 7.34. 2.2d 11-Amino-8,9,10,12-tetrahydro-12-p-tolyl-7Hchromeno[2,3-b]quinolin-1-ol (entry 5): mp: 285286. IR (KBr): $3455,3365,2910,1613,1433,1218$, $1165 \mathrm{~cm}^{-1} .{ }^{1} \mathrm{H}$ NMR $\left(100 \mathrm{MHz}, \mathrm{DMSO}-d_{6}\right): \delta=1.60$ (m, 4H, $\left.\mathrm{CH}_{2}\right), 2.20\left(\mathrm{~s}, 3 \mathrm{H}, \mathrm{CH}_{3}\right), 2.35\left(\mathrm{~m}, 2 \mathrm{H}, \mathrm{CH}_{2}\right)$, $2.55\left(\mathrm{~m}, 2 \mathrm{H}, \mathrm{CH}_{2}\right), 5.40(\mathrm{~s}, 1 \mathrm{H}, \mathrm{CH}), 6.10\left(\mathrm{~s}, 2 \mathrm{H}, \mathrm{NH}_{2}\right)$, 6.45-7.20 (m, 7H, ArH), 9.63 (s, 1H, OH). Anal. Calcd for $\mathrm{C}_{23} \mathrm{H}_{22} \mathrm{~N}_{2} \mathrm{O}_{2}$ : C, 77.07; H, 6.19; N, 7.82. Found: C, $76.73 ; \mathrm{H}, 6.30 ; \mathrm{N}, 7.71$.

\section{Results and discussion}

Here, a novel, one-pot, four-component coupling of resorcinol, malononitrile, aromatic aldehydes and cyclohexanone to prepare pyrano[2,3-b]pyridine derivatives using 4-Nitro-2,6-diacetylpyridinebis(2,4,6trimethylanil)) $\mathrm{FeCl}_{2}$ under solvent-free using ultrasonic irradiation is reported. First of all, the one-pot reaction of resorcinol, malononitrile, benzaldehydes and cyclohexanone was carried out under solvent-free 


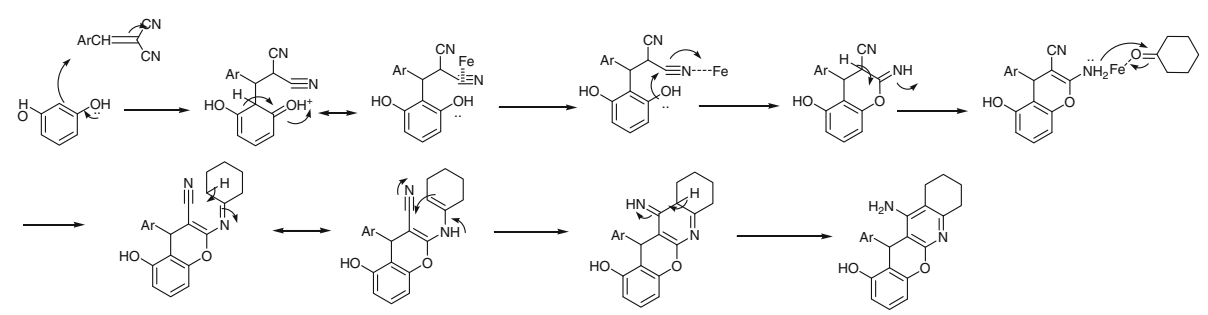

Scheme 2. Reasonable mechanism for the one-pot synthesis of pyrano[2,3- $b]$ pyridines.

and ultrasonic irradiation. The reaction was considered as a standard model reaction. In order to evaluate the effect of ultrasonic irradiation (table 1, compound 1), firstly, the model reaction was examined without ultrasound at room temperature. Almost moderate yield $(44 \%)$ with prolonged reaction time $(5 \mathrm{~h})$ was found, and when the reaction was carried out under ultrasonication at room temperature, excellent yield of the corresponding pyranopyridine was obtained (90\%) within short reaction time (35 $\mathrm{min})$. Furthermore, no by-product was detected when the reaction was carried out under ultrasonic irradiation.

The scope and generality of this process is illustrated with respect to various aromatic aldehydes. Aromatic aldehydes substituted with either electrondonating or electron-withdrawing groups have undergone smooth reaction and gave the corresponding pyrano[2,3-b]pyridine in moderate to excellent yields.

The proposed mechanism is depicted in scheme 2 . The aldehyde first is condensed with malononitrile to afford $\alpha$-cyanocinnamonitrile by Knoevenagel addition. Resorcinol C-alkylation gives an intermediate which cyclizes via nucleophilic attack of $\mathrm{O}$ atom on the cyano moiety following to protonation and rearrangement to produce the intermediate of 2-amino-3-cyano7-hydroxy-4-substituted-4H-chromene which could be isolated to investigate the mechanism. Subsequently, cyclohexanone reacted with the chromene and as shown the pyrano[2,3-b]pyridine is synthesized through heterocyclization.

\section{Conclusion}

Four-component green coupling reactions of resorcinol, malononitrile, aromatic aldehydes and cyclohexanone efficiently proceeded in the presence of (4-nitro-2,6diacetylpyridinebis(2,4,6-trimethylanil) $) \quad \mathrm{FeCl}_{2}$ under ultrasonic irradiation and solvent-free conditions. The catalyst exhibited high activity and the reactions were clean and highly selective affording exclusively pyrano[2,3-b]pyridine in moderate to excellent yields.

\section{References}

1. Azuine $M$ A, Tokuda H, Takayasu J, Enjyo F, Mukainaka T, Konoshima T, Nishino $\mathrm{H}$ and Kapadia $\mathrm{G}$ 2004 J. Pharmacol. Res. 49161

2. Srivastava S K, Tripathi R P and Ramachandran R 2005 J. Biol. Chem. 28030273

3. Toshiro S and Noriko W 1995 Eur. Pat. Appl. EP 647445 A1 19950412

4. Sangshetti J, Kokaren N, Kotharkara S A and Shinde D B 2008 J. Chem. Sci. 120463

5. Ukawa K, Ishiguro T, Kurik H and Nohara A 1985 Chem. Pharm. Bull. 334432

6. Dushyant S R and Krishna N S 2010 ARKIVOC 305

7. Sunkyung L, Sun M C, Kyu Y Y, Nakjeong K and Chang H 2005 Bull. Korean Chem. Soc. 264

8. Khlebinkov V, Patel K, Zhou X, Reddy M M, Su Z, Chiacchia F S and Hansen H C 2005 Tetrahedron $\mathbf{6 5}$ 6932

9. Singh V, Sapehiyia V and Kad G L 2003 Synthesis 2 198

10. Li J T, Bian Y J, Zang H J and Li T S 2002 Synth. Commun. 32547

11. Robin M, Pique V, Faure R and Glay J P $2002 \mathrm{~J}$. Heterocycl. Chem. 391083

12. Rajagopal R, Jarikote D V and Srinivasan K V 2002 Chem. Commun. 616

13. Zohuri G H, Seyedi S M, Sandaroos R, Damavandi S and Mohammadi A 2010 Catal. Lett. 140160

14. Damavandi S 2011 Heterocycl. Commun. 1779

15. Eshghi H, Zohuri G H and Damavandi S 2011 European J. Chem. 2100 